\title{
Historiografia, memória e ensino de história: percursos de uma reflexão
}

\author{
Historiography, memory and history teaching: pathways of a reflection
}

\author{
Maria da Glória de Oliveira \\ mgloriaprof@gmail.com \\ Professora adjunta \\ Universidade Federal Rural do Rio de Janeiro \\ Campus Seropédica - BR 465, km 7 \\ 2389-0000 - Seropédica - RJ \\ Brasil
}

\section{Resumo}

Em um de seus últimos trabalhos, Manoel Luiz Salgado Guimarães abordou as tensões e os paradoxos das relações entre a escrita e o ensino da história, entendendo ambas as operações como marcas distintivas de duas dimensões indissociáveis, da construção do conhecimento histórico e do próprio ofício do historiador. No presente artigo, proponho um retorno a textos por ele publicados a partir do final dos anos 1990, através dos quais apontarei alguns dos problemas teóricos que perpassaram as suas reflexões em torno da história escrita e da história ensinada como formas de configuração de sentido e de usos do passado. O objetivo é situar as proposições de Manoel Salgado acerca do ensino da história nos desdobramentos de suas proposições teóricas sobre a historiografia.

\section{Palavras-chave}

Historiografia; Memória; Ensino de história.

\begin{abstract}
In one of his last published texts, Manoel Luiz Salgado Guimarães addressed the tensions and paradoxes involved in the relationship between history writing and history teaching, and presented both operations as constitutive of two inseparable dimensions of the construction of historical knowledge and the historian's craft. This article aims at revisiting the texts Guimarães published from the late 1990s on, pointing to some of the theoretical problems that have permeated his reflections on history education and writing as forms of meaning making, as well as ways of using the past. My purpose is to show that Guimarães' considerations on history teaching is one of the unfoldings of his theoretical propositions about historiography.
\end{abstract}

Keywords

Historiography; Memory; History teaching.

Recebido em: 3/10/2013

Aprovado em: 28/10/2013 
[...] atemorizados por uma barbárie cada vez mais presente em nossos cotidianos, repensar a história e seu ensino pode nos ajudar a refazer nossa humanidade esgarçada, tornando o passado não o lugar seguro para as respostas que nos angustiam, mas a fonte [...] para a nossa ação no mundo (GUIMARÃES 2009, p. 50).

Com as palavras acima, Manoel Luiz Salgado Guimarães encerrava a conferência de abertura do Seminário Ensino da História: Memória e Historiografia, na Universidade Federal Fluminense em 2008, legando-nos uma instigante reflexão acerca das relações entre a escrita e o ensino da história na contemporaneidade. ${ }^{1}$ Naquele momento, o tema do ensino já vinha sendo explorado como objeto profícuo de pesquisa entre os historiadores, o que se confirma com a multiplicidade de trabalhos acadêmicos e eventos a ele dedicados no Brasil, nos últimos anos. Por conseguinte, mais do que assunto de relevância incontestável, não poderíamos pensar, inspirando-nos nos argumentos de François Hartog, que a evidência da história, para além de denotar a consagração institucional de suas ambições disciplinares científicas, não se atestaria nos modos como ela, além de "relatada, escrita e feita" (HARTOG 2011, p. 11), também passou a ser ensinada?

O debate em torno da história como matéria escolar, sob muitos aspectos, sempre esteve associado à constatação de uma defasagem entre o conhecimento histórico produzido segundo as regras da pesquisa científica, especializada e acadêmica e os seus "resultados" difundidos pelo sistema de ensino ou através da circulação pública e massiva, visando certos fins pedagógicos e, de modo mais explícito, as demandas sociais do tempo presente. ${ }^{2}$ Afirmando não ter a pretensão de adentrar no problema das relações entre a história escrita, em grande parte fabricada no âmbito da universidade, e a história ensinada nas escolas, Manoel Salgado explora as tensões e os paradoxos entre ambas a partir de uma indagação sobre as condições que tornaram possível a própria constituição da história como objeto de uma pedagogia escolar, isto é, como "matéria efetivamente organizada sob um sistema que prevê seu ensinamento, sua transmissão" (GUIMARÃES 2009, p. 36). Sob tal perspectiva, pensar o ensino do saber histórico implica que já estejamos situados em um momento particular da própria história da história, quando ela se apresenta instituída como disciplina científica para a qual as sociedades modernas dirigem demandas específicas. Portanto, é no conjunto dessas demandas que acompanham a sua constituição disciplinar que também se situa a configuração da história como objeto pedagógico e componente obrigatório do currículo escolar (GUIMARÃES 2009, p. 37).

Como tema pouco associado à obra de Manoel Salgado, interessa-me neste

\footnotetext{
${ }^{1}$ O Seminário Ensino da História: Memória e Historiografia ocorreu entre 2 e 4 de junho de 2008, como parte das atividades do projeto Culturas políticas e Usos do passado - Memória, Historiografia e Ensino de História, que reuniu um grupo de professores de diferentes universidades do Rio de Janeiro. O evento deu origem ao livro A escrita da história escolar: memória e historiografia, que reúne os trabalhos então apresentados, entre eles, a conferência de abertura de Manoel Salgado (ROCHA; MAGALHÃES; GONTIJO 2009).

2 Nas palavras de Beatriz Sarlo, a história não acadêmica, mesmo aquela praticada por profissionais da área, "escuta os sentidos comuns ao presente, atende as crenças de seu público e se orienta em função delas", conectando-se ao "imaginário social contemporâneo" (SARLO 2005, p. 15).
} 
artigo identificar os percursos que o levaram a refletir acerca da história escrita e da história ensinada, situando tais reflexões no desdobramento das abordagens sobre historiografia e memória, que marcaram as suas contribuições seminais como pesquisador da cultura histórica oitocentista. O que proponho, portanto, é um ensaio de leitura de artigos publicados entre o final da década de 1990 e início dos anos 2000, nos quais despontam proposições, escolhas teóricas e, sobretudo inquietações próprias de um professor-historiador no exercício de seu ofício.

\section{Caminhos para a historiografia em tempos de crise}

Como então não postular a incômoda, mas indispensável pergunta acerca da relação que nosso texto mantém com este conjunto de eventos e experiências passadas? E como não ver aí um caminho para se pensar diferentemente a historiografia, entendida enquanto escrita da história, agora percebida como atividade mais complexa e nada simplista, como se escrever sobre o passado fosse apenas 0 ato de expressar num texto uma realidade existente fora dele? (GUIMARÃES 1998, p. 15).

Dez anos após a publicação do artigo "Nação e civilização nos trópicos", Manoel Salgado apresenta aquelas que seriam as suas primeiras reflexões sobre a historiografia, em dois textos publicados em 1998 e 2000 respectivamente, apontando os caminhos e as abordagens possíveis para uma delimitação renovada das especificidades dessa área entre os estudos históricos. ${ }^{3}$ Escrito no final do milênio, "Repensando os domínios de Clio: as angústias e ansiedades de uma disciplina" (1998) sugere, em seu próprio título, o diagnóstico geral de um período de dúvidas e incertezas no âmbito disciplinar, mas que, potencialmente, também se apresentava como oportunidade para os historiadores repensarem o próprio campo e o exercício de seu ofício. No segundo artigo, "Usos da história: refletindo sobre identidade e sentido" (2000a), a referência ao contexto das celebrações dos 500 anos da chegada dos portugueses ao Brasil, serve como ponto de partida para o aprofundamento da análise das relações entre história e memória nos processos de fabricação simbólica dos laços de identidade coletivos, tema apenas esboçado no texto anterior. ${ }^{4}$ Considero relevante mapear os percursos argumentativos registrados nesses textos, de modo a pontuar algumas das escolhas teóricas que se delinearam a partir do trabalho sistemático e reflexivo que Manoel Salgado dedicou ao problema da historiografia.

Com a expressão "crise da história" que resumia difusamente o contexto historiográfico na França dos anos 1980/1990, também se poderia denotar o "tempo dos retornos" (da narrativa, do acontecimento, do político e do biográfico), o momento de "reviravolta epistemológica" geral no campo das ciências sociais, ou ainda a "virada crítica", alusão direta ao título do editorial de 1988 da revista dos Annales, escrito como reação propositiva frente aos debates em torno das

\footnotetext{
3 Publicado no primeiro volume da Revista Estudos Históricos, em 1988, como parte do dossiê "Caminhos da historiografia", "Nação e civilização nos trópicos: o Instituto Histórico e Geográfico Brasileiro e o projeto de uma história nacional" tornou-se um texto paradigmático e de ampla recepção para os estudos da escrita histórica brasileira, consistindo no resumo dos argumentos da tese Historiografia e nação no Brasil (1838-1857), defendida por Manoel Salgado no ano anterior, na Universidade de Berlim, sob a orientação de Hagen Schulze. ${ }_{4}^{4}$ Para uma relação completa da produção bibliográfica de Manoel Salgado, ver GUIMARÃ̃ES 2011, p. 277-280.
} 
capacidades explicativas da história e da sua escrita (DELACROIX 2012, p. 338). No artigo de 1998, Manoel Salgado dialoga diretamente com autores que, naquela década, reconheciam uma guinada reflexiva entre os historiadores, como efeito dos questionamentos a certo modelo de ciência histórica, sobretudo ao projeto de escrita da história fundado em grandes unidades de identificação, como a nação moderna, e nos princípios aglutinadores implícitos na ideia de progresso (GUIMARÃES 1998, p. 6). Ainda na introdução do texto, duas referências servem para demarcar a linha de reflexão proposta: a primeira delas é Pierre Nora e, mais especificamente, a constatação de que a história atingira uma era epistemológica, com o advento de uma preocupação historiográfica no interior da disciplina o que, de modo particular, se consubstanciava nos trabalhos que compunham a obra coletiva Les Lieux de mémoire, dirigida pelo historiador francês. Nora reaparecerá na parte final do artigo, como um dos autores chave para se pensar novas possibilidades de abordagem para o estudo da historiografia.

Outro autor que também fornece os argumentos iniciais do texto é Jörn Rüsen. Segundo a leitura de Manoel Salgado, na proposta de uma tipologia das formas de historiografia ou modos de escrita histórica, o historiador alemão alçava a reflexão acerca do que fazemos quando escrevemos história ao estatuto de problema teórico fundamental, remetendo a uma investigação acerca dos processos de constituição de sentido e significado para o passado. Isso porque o exercício teórico acerca do fazer historiográfico pressupunha, antes de tudo, considerar a escrita da história em sua "condição fundamental de historicidade, o seu lugar no tempo e entre os homens, sua contingência", o que significava não esquecer que o nosso ofício não se situa para além ou fora desta história (GUIMARÃES 1998, p. 7). E o primeiro passo neste sentido seria reconhecer as condições históricas dessa constituição disciplinar, indelevelmente marcada pela convicção no progresso como um dado inerente e distintivo da experiência humana e das sociedades ocidentais contemporâneas. Assim, "nossa disciplina institucionalizada e definida como campo autônomo de saber no auge desta crença no século XIX, parece ter se transformado na memória deste mesmo progresso, como uma escrita que reafirmasse a cada passo uma natureza intrínseca que se desvelasse a cada novo período histórico" (GUIMARÃES 1998, p. 8). Sabe-se, contudo, que tal projeto de ciência, fundado na confiança das potencialidades explicativas do conhecimento histórico, não permaneceu infenso a questionamentos críticos que, pelo menos desde o final dos Oitocentos, puseram em xeque certas expectativas e demandas sociais dirigidas à função pedagógica e emancipadora da história.

Mas, levando em conta que, no final dos anos de 1990, a palavra "crise" aglutinava experiências que extrapolavam as inquietações peculiares e exclusivas do campo disciplinar, quais seriam os caminhos possíveis para a renovação da historiografia como campo efetivo de pesquisa? Como reivindicar a legitimidade e a relevância dos estudos dessa natureza? De imediato, Manoel Salgado reconhecia na historiografia uma área de estudos pouco valorizada no interior da disciplina histórica, nas suas palavras, "uma 'prima pobre', marcada por uma 
forte tradição positivista que se contentava em elaborar catálogos de autores e obras" (GUIMARÃES 1998, p. 10-11). Ademais, a escassa inovação desses estudos decorreria de um procedimento que se tornara comum nos trabalhos historiográficos e nos modos de se conceber a história da disciplina, segundo o qual

o simples ato de identificação de um autor e seu contexto de produção dariam conta suficiente da inteligibilidade da história produzida, sem que uma problematização da obra enquanto ato de criação e construção de um passado estivesse na pauta destas investigações (GUIMARÃES 1998, p. 11).

No caso brasileiro, era necessário reconhecer nos trabalhos de José Honório Rodrigues, ainda na década de 1950, o caráter pioneiro e sintomático do advento de certa preocupação historiográfica em nossos meios acadêmicos, a despeito do seu compromisso com uma visão cronológico-evolutiva da ciência histórica como princípio subjacente à seleção e canonização dos historiadores e suas obras. É importante destacar que, no artigo de 1998, os dois únicos e breves parágrafos dedicados ao autor de $A$ pesquisa histórica no Brasil servem para delimitar o que se configurava como "tradição" no campo dos estudos historiográficos, ou seja, a confecção de repertórios e balanços críticos, frente a qual era possível contrapor outras perspectivas de abordagem, cuja novidade estava em tomar "a escrita da história como objeto da própria história, constituindo-a, portanto, enquanto 'problema'"' (GUIMARÃES 1998, p. 12). ${ }^{5}$

Sete anos mais tarde, o argumento reaparece no artigo "Historiografia e cultura histórica: notas para um debate" (GUIMARÃES 2005). Nele, a contribuição de José Honório será objeto não apenas de avaliação mais detida e aprofundada, mas igualmente de uma problematização acerca de alguns pressupostos do seu empreendimento historiográfico. Neste sentido, vale a pena nos desviarmos do artigo de 1998, abrindo espaço para a passagem extraída do texto posterior, no qual se evidencia uma inflexão importante nas análises de Manoel Salgado, na medida em que ele reavalia a confecção de repertórios historiográficos, enfatizando, de modo mais incisivo, o seu papel na construção da memória disciplinar:

Se a organização sistemática destes catálogos não deve ser confundida com
o trabalho de historiografia, são inegáveis a sua utilidade e necessidade
como forma de organização de repertórios a serem trabalhados pela
pesquisa historiográfica. Por outro lado, não podemos descuidar de nos
interrogar acerca do olhar que empreende estes mesmos repertórios,
num movimento em que ao mesmo tempo em que os apresenta, os
apreende segundo certa chave de leitura, constituindo a partir daí uma
memória acerca destes autores e obras. Portanto, o catálogo, longe de
ser uma atitude neutra do pesquisador-compilador, sugere um conjunto
de procedimentos e dispositivos de leitura e compreensão de autores e
obras segundo uma memória que se quer objetiva (GUIMARÃES 2005, p.
37, grifos meus). ${ }^{6}$

5 Poderíamos acrescentar, a propósito, que essa tradição de estudos historiográficos, tal como assinalada por Manoel Salgado, forjou-se a partir de escolhas que, de certa forma, pareciam contrariar as advertências formuladas em 1914 pelo autor de um clássico das pesquisas do gênero, Eduard Fueter, quando postulou que uma história da historiografia deveria ser "outra coisa do que um léxico de historiadores" (FUETER 1914, p.II). 6 Neste sentido, na proposta de ultrapassar a confecção de catálogos e balanços bibliográficos que, tradicionalmente, se confundiram com os estudos de historiografia, se era imprescindível a demarcação dos 
Quando retomamos a leitura do artigo "Repensando os domínios de Clio" (1998), é possível perceber, em sua segunda parte, a mobilização de autores que, naquele momento, ofereciam elementos para que a historiografia se alçasse a um patamar diverso e distinto da "tradição dos catálogos de autores e obras", convertendo a escrita da história e o próprio trabalho do historiador em objetos de um novo olhar historiográfico. No conjunto dessas referências, o primeiro nome que sugeria possibilidades de renovação do trabalho com a historiografia era o de Michel de Certeau, cujas formulações tornavam incontornáveis a compreensão do texto dos historiadores como resultado de uma fabricação e a abordagem do discurso histórico como prática social submetida a regras e disposições históricas, contingentes e, portanto, sujeitas à temporalidade. ${ }^{7}$

Por uma perspectiva diversa, a desnaturalização da escrita da história e o questionamento do modelo cientificista do conhecimento histórico também se apresentavam como contribuições decisivas advindas, por um lado, dos debates em torno da narrativa, iniciados no começo dos anos de 1970 e, por outro, da chamada virada linguística, deflagrada no âmbito da filosofia analítica anglo-saxã, a partir da qual a linguagem deixaria de ser concebida como um meio mais ou menos transparente para a representação de uma realidade "objetiva" e externa a ela mesma. ${ }^{8}$ Nesse contexto, a Meta-história, de Hayden White, publicada em 1973 e editada pela primeira vez no Brasil em 1992, mantinha-se como uma referência obrigatória $e$, sob muitos aspectos, complementar às reflexões de Certeau, apresentando-se como uma segunda via de abordagem renovada para a historiografia, a despeito do caráter provocativo e polêmico da tese do historiador norte-americano acerca da dimensão ficcional do texto historiográfico e, por conseguinte, da difícil recepção e escasso reconhecimento entre os seus pares. Com as proposições de White, despertava-se do nobre sonho rankiano que postulava o realismo como meta e marca distintiva do texto histórico. Em decorrência disso, "a dimensão textual da produção do historiador passa[va] a ser o centro da análise historiográfica, a partir das regras próprias à sua elaboração e dos modelos disponíveis em uma determinada cultura para a representação textual do mundo" (GUIMARÃES 1998, p. 15).

Ainda no elenco de referências assinaladas por Manoel Salgado, destacam-se as reverberações da polêmica narrativista para além do contexto francês e anglo-saxão. A primeira, no ambiente acadêmico alemão, entre o final dos anos de 1970 e início de 1980, reunira um grupo de historiadores no evento sobre "Formas de escrita da história", resultando na publicação homônima, sob a organização de Reinhart Koselleck, Heinrich Lutz e Jörn Rüsen. Outra recepção não menos

seus objetos, a formulação de problemas e de pautas específicas de investigação, igualmente se fazia necessário o trabalho de edição crítica e comentada de textos como forma de se constituir um corpus de fontes possíveis de pesquisa. Essa preocupação estava na base de um dos importantes projetos de Manoel Salgado, que se concretizou postumamente com a publicação do Livro de fontes de historiografia brasileira, composto por discursos, dissertações e memórias, publicados na revista do IHGB, ao longo do século XIX, transcritos em sua ortografia e pontuação originais e acrescidos de elucidativas notas do seu organizador (GUIMARÃES 2011).

7 O texto de Certeau, citado por Manoel Salgado, corresponde à primeira versão, incluída na edição brasileira da obra organizada por Jacques Le Goff e Pierre Nora, História: novos problemas, em 1976, dois anos após a publicação no original francês Faire de l'histoire. O estudo, revisto e ampliado, reapareceu sob o título "A operação historiográfica", no livro L'Écriture de l'histoire, de 1975, cuja primeira edição no Brasil data de 1982.

8 Para uma análise do impacto teórico da virada linguística na história intelectual, ver PALTI 2012, p. 19-167. 
significativa do debate, desta vez em solo brasileiro, estaria no colóquio com especialistas de diferentes campos de pesquisa em torno do tema Narrativa, Ficção e História, na Universidade do Estado do Rio de Janeiro, em 1987.9

Em seu conjunto, todas essas indicações assinalavam uma espécie de fim de uma "idade da inocência" das abordagens da historiografia e da própria escrita da história, que passava a ser compreendida, a partir de então, como ato de configuração de sentido. Portanto, para além de buscar o seu sentido em um "contexto", procedimento tão familiar ao historiador, "o próprio texto de história ganha[va] uma identidade própria, não bastando uma mera referência a elementos extratextuais que guardariam a razão última de ser do próprio texto do historiador para a sua explicação" (GUIMARÃES 1998, p. 17).

Na conclusão do artigo de 1998, a retomada da referência a Pierre Nora deixa em aberto, ainda de forma difusa e bastante abreviada, aquela que seria a terceira indicação para uma abordagem renovada dos estudos de historiografia. $\mathrm{Na}$ leitura de Manoel Salgado, o conceito de "lugares de memória" fornecia uma chave operatória promissora como modo de abordar o texto historiográfico, entendido como resultado de uma operação discursiva, entre tantas outras práticas sociais e, portanto, não mais percebido apenas como discurso dotado das prerrogativas de neutralidade e cientificidade, mas como objeto que, saturado de uma dimensão simbólica por fazer parte do imaginário social, também poderia ser submetido à dessacralização.

As relações entre memória e historiografia se constituíram em um dos 136 eixos cruciais e mais profícuos das reflexões de Manoel Salgado desenvolvidas em seus trabalhos posteriores. É nesta direção que, cinco anos mais tarde, ele será incisivo em argumentar que "uma tarefa desmistificadora por excelência" estava reservada à historiografia como campo de reflexão, na medida em uma história da história, menos do que reconstituir mitos, pressupunha perceber a escrita da história como sendo ela também "vítima das construções da memória" (GUIMARÃES 2003, p. 22). Por essa perspectiva, chegava-se a uma circunscrição mais abrangente para a historiografia, definida por ele como "investigação sistemática acerca das condições de emergência dos diferentes discursos sobre o passado", o que significava reconhecer não somente a historicidade do próprio ato da escrita histórica, mas igualmente percebê-la como resultado de disputas entre memórias e como parte das lutas travadas nas sociedades pela atribuição de sentido ao passado (GUIMARÃES 2003, p. 23).

Contudo, se na usual construção sistemática de balanços e inventários historiográficos era possível detectá-la de modo mais explícito como um princípio ordenador da seleção e canonização de autores e obras, como pensar o papel da memória e do seu trabalho paciente e tantas vezes insidioso, no âmbito dessa nova forma de abordar a historiografia, delimitada a partir de uma démarche diversa, na qual os textos de história deixavam de ser meros pretextos para

${ }_{9}^{9}$ O Colóquio, promovido pelo Instituto de Letras da UERJ, com coordenação de Dirce Cortes Riedel, consistia em exposições de trabalhos, acompanhadas por comentários e debates. Entre os participantes estavam Benedito Nunes, Bento Prado Júnior, Luiz Costa Lima, Ricardo Benzaquen, Nicolau Sevcenko, Francisco Iglésias e José Américo Motta Pessanha. Os textos completos do evento foram reunidos em RIEDEL 1988. 
se converterem em objetos centrais de investigação de problemas e questões acerca das elaborações de sentido para o passado?

\section{Quebrando o espelho da memória disciplinar}

É preciso que a própria escrita da história se submeta ao rigor do exame crítico como forma de dessacralizarmos uma memória construída acerca desta mesma escrita. Reconheço não ser este um esforço simples, uma vez que implica em repensar os fortes traços narcísicos que marcaram a constituição da disciplina, e a tarefa de quebrar o espelho implica em um doloroso repensar dos rumos de nosso ofício (GUIMARÃES 2000a, p. 22, grifos meus).

De um modo talvez surpreendente, no desfecho do artigo de 1998, Manoel Salgado sugere que uma história da história poderia contribuir para a disciplina "enfrentar as angústias decorrentes de sua forte dimensão narcísica..." (GUIMARÃES 1998, p. 20). A digressão, deixada em suspenso naquele texto, será retomada dois anos depois, quando ele volta a mobilizar a metáfora psicanalítica, grifada na passagem em epígrafe acima, desta vez deixando mais explícita a analogia entre o narcisismo, momento basilar do processo de estruturação psíquica dos indivíduos, e os processos que marcaram não somente a conquista da autonomia da história como disciplina no Oitocentos, mas as condições para a afirmação de sua proeminência entre as ciências humanas e sociais, ao longo do século seguinte. ${ }^{10}$

O contexto de publicação do artigo sobre os usos da história, no ano 2000 - começo do novo milênio que coincidia com as celebrações dos 500 anos do Brasil - não poderia ser mais oportuno para abordar as intrincadas relações entre as construções da memória e a história, operação intelectual privilegiada para investigar criticamente essas construções em sua historicidade (GUIMARÃES 2000a, p. 21). ${ }^{11}$ No entanto, mais do que enfatizar as pretensões dos historiadores em "retirar dos altares" os objetos que a memória celebra e reverencia, tornava-se necessário interrogar as relações entre a história e a vida social e, sobretudo os significados políticos de certos usos da disciplina.

Se, desde o final dos anos 1990, uma tomada de consciência se evidenciava na postura reflexiva dos historiadores acerca de suas operações e pressupostos de escrita e pesquisa, também tornava necessária, nas palavras de Manoel Salgado, "a tarefa de quebrar o espelho" e, sobretudo desnaturalizar a imagem de uma história-ciência que, tal como no mito narcísico, permanecera

\footnotetext{
${ }_{10} \mathrm{Na}$ elucidação dessa metáfora, vale retomar o conceito lapidar da teoria psicanalítica freudiana, tal como formulado em Totem e Tabu [1913], onde Freud afirma que o narcisismo não é meramente um estágio passageiro na história libidinal do sujeito, e sim uma estrutura permanente que continua a existir apesar das reestruturações libidinais posteriores (FREUD 2006, p. 92). No conjunto de trabalhos de Manoel Salgado, uma apropriação mais direta de textos do criador da psicanálise, como Totem e Tabu e Moisés e o monoteísmo, encontra-se em uma parte do capítulo "O presente passado: as artes de Clio em tempos de memória", quando analisa o papel da evocação e da lembrança ritualizada como atos constitutivos e fundadores da vida coletiva (GUIMARÃES 2007, p. 32-34).

${ }_{11}$ Cabe destacar que, além do texto referido, ainda no ano 2000, Manoel Salgado publicou dois artigos que se tornaram referências primorosas e seminais para a pesquisa em história da historiografia: "Reinventando a tradição: sobre antiquariato e escrita da história" (2000b) e "História e natureza em von Martius: esquadrinhando o Brasil para construir a nação" (2000c).
} 
seduzida e subjugada pela memória de sua própria potência institucional e triunfo disciplinar. Impunha-se, então, um conjunto de interrogações, a começar pela historicidade da própria disciplina e "dos entrelaçamentos entre projetos de escrita sistemática das lembranças do passado e a produção da memória social" e, sobretudo, sobre os usos e sentidos políticos do conhecimento fabricado pelos historiadores (GUIMARÃES 2000a, p. 22-23).

Já assinalada no artigo de 1998, a abordagem crítica dos "mitos de fundação" da ciência histórica e de sua subsequente hegemonia, desde o século XIX, entre as demais ciências sociais, consistiria no primeiro passo para dessacralizar certa memória construída em torno da disciplina. No entanto, o que se formula de modo mais consistente no texto de 2000 é a constatação de que tal tarefa implicava necessariamente a ampliação do escopo reflexivo para além do âmbito das questões endógenas ao campo disciplinar, ou seja, uma história da história não poderia deixar de ser pensada também como uma crítica da cultura. ${ }^{12}$

E será a partir desta perspectiva que, no texto de 2000, Manoel Salgado retomará as contundentes objeções dirigidas à história e aos seus usos políticos, formuladas por Paul Valèry no contexto entre guerras do século XX. Antes dele, despontando como um dos primeiros críticos do historicismo, Nietzsche desferira o seu ataque contra o fardo incômodo de uma cultura impregnada pelos excessos da consciência histórica, como parte das suas considerações intempestivas. Cerca de meio século mais tarde, em 1932, com a célebre frase na qual se referia ao "produto mais perigoso já elaborado pela química do intelecto", coube ao escritor 138 francês expressar a postura que, naquele momento, se situava em contraponto à imagem dominante acerca da história e de seu papel hegemônico nos processos de produção de sentido, questionando a sua capacidade explicativa do presente e de projeção do futuro (GUIMARÃES 2000a, p. 23-29). A perigosa química, de que falava Valèry, consistia na combinação entre a história escrita sob um ponto de vista nacional, capaz de oferecer as suturas simbólicas necessárias à tessitura dos laços identitários coletivos, mas que, concomitantemente, pretendia ser conhecimento alicerçado em bases realistas, objetivas e científicas. Assim, como parte dessa cultura histórica, articulada ao quadro amplo das transformações das sociedades ocidentais desde a segunda metade do século XVIII, herdamos um modo de nos relacionar com o passado, por meio do qual passamos a evocá-lo como fonte primordial de explicação e lugar de construção de sentido para o presente e projeções futuras. Nesse contexto,

o esforço sistemático de lembrar o passado torna-se uma política de Estado, acionando um conjunto diversificado de estratégias rememorativas: as comemorações e ritualizações do passado, compreendendo os feitos e os grandes homens de uma coletividade nacional; uma escrita da

\footnotetext{
12 A esse respeito, é possível identificar uma aproximação das reflexões de Manoel Salgado daquelas formuladas anteriormente por Afonso Carlos Marques dos Santos. Em artigo publicado em 1986, já assinalando uma recepção dos argumentos de Pierre Nora, Santos questionava o papel da memória no debate teórico acerca de uma historiografia que se pretendia crítica e renovadora e concluía que uma abordagem da produção histórica ultrapassava o território específico dos historiadores, devendo se inscrever em um estudo crítico mais amplo sobre a cultura (SANTOS 2007, p. 94). Para uma análise e avaliação da contribuição dos artigos de Afonso Carlos na constituição da área de pesquisa em história da historiografia no Brasil, ver ARAUJO 2012.
} 
História nacional assim como os dispositivos disciplinares capazes de torná-la ensinável, matéria de uma pedagogia do novo cidadão nacional (GUIMARÃES 2000a, p. 27, grifos meus).

Com a passagem acima, chega-se a uma pista importante acerca tema do ensino, na medida em que as condições que conformam a história como matéria pedagógica também se definem no próprio momento de sua constituição como ciência e disciplina. Antes de avançar sobre esse ponto, outro aspecto que merece ser assinalado no artigo diz respeito mais diretamente à forma com que Manoel Salgado amplia os seus argumentos em torno da historiografia como objeto e campo de pesquisa. Se, no artigo de 1998, a referência à noção de "lugares de memória" de Pierre Nora prenunciava uma possível chave de leitura para a renovação dos estudos historiográficos, no texto de 2000, a menção ao conceito de memória cultural, cunhado por Jan Assmann, em um estudo publicado na Alemanha no ano anterior, serve de aporte teórico para demarcar o afastamento definitivo da historiografia como campo de pesquisa das "tentações positivistas ou da tradição que associava a reflexão historiográfica à confecção de um minucioso catálogo de autores e obras" (GUIMARÃES 2000a, p. 32). O abandono da concepção naturalizada da história como dotada de evidência própria, assegurada pela existência mesma do passado, implicava considerá-la como parte dos processos sociais e coletivos de elaboração da experiência da passagem do tempo.

O passado só pode efetivamente emergir como resultado, portanto, de uma relação que as diferentes sociedades estabelecem com o tempo. Se esta relação é ela mesma histórica, o que significa afirmar ser diversa para cada sociedade no tempo, cabe a uma historiografia como disciplina investigar estas diferentes e diversas maneiras de constituição do passado, e neste sentido, podemos pensá-la como integrando os estudos em torno da memória cultural (GUIMARÃES 2000a, p. 32)

Tratava-se, portanto, de circunscrever um inventário sistemático de problemas e questões envolvidos nessa elaboração da experiência dos tempos pretéritos. Para torná-la efetiva em seus objetivos, concluía Manoel Salgado, a historiografia como área de pesquisa deveria necessariamente dialogar com uma história da cultura como condição indispensável "para cumprir sua tarefa de crítica às memórias construídas e, por vezes, naturalizadas" (GUIMARÃES 2000a, p. 34).

É importante perceber como, sete anos mais tarde, a noção de cultura histórica se apresenta como eixo crucial para os estudos de historiografia tal como os concebia Manoel Salgado. Também formulada por Assmann, no sentido de uma "cultura da lembrança", a noção abarcava as diferentes representações acerca do tempo, "figurado para as sociedades que o experimentam segundo os significados, eles mesmos temporalmente produzidos" e, nesta chave, era possível compreender a historiografia em seu sentido mais ampliado como "forma de elaboração do conhecimento sobre o passado por meio de uma narrativa metodologicamente controlada" (GUIMARÃES 2007, p. 36). Naquele momento, os investimentos sociais nas tarefas da memória, que já se evidenciavam nas 
práticas disseminadas de patrimonialização e musealização do passado, como parte das demandas políticas do tempo presente, também faziam pensar em uma sobrevalorização do exercício da lembrança e da recordação em detrimento da produção de conhecimento e, por conseguinte, de uma compreensão crítica das experiências históricas. Em 2007, Manoel Salgado incluía tais questões na pauta de um projeto de história da historiografia que, segundo ele, deveria necessariamente articular as noções de cultura histórica, memória e usos do passado. E assinalava, no desdobramento dessa discussão, o tema das relações entre a produção do passado em sua forma acadêmica e como objeto da pedagogia escolar.

\section{História escrita, história ensinada}

Qual o sentido, nos tempos que correm, do exercício deste ofício, tão recente em termos disciplinares, mas tão antigo como gênero de escrita, uma vez que seu nascimento pode ser situado entre os gregos da polis democrática no século $V$ antes de Cristo? E, sobretudo como pensá-lo, hoje, como prática pedagógica escolar e universitária? (GUIMARÃES 2000a, p. 34).

O ensino da história será o objeto central da conferência proferida em 2008, cujas palavras de encerramento serviram de epígrafe inicial para este artigo. A discussão, segundo Manoel Salgado, adquiria relevância, na medida em que ultrapassava o âmbito das preocupações restritas aos especialistas em construir narrativas históricas, tornando-se premente como reflexão mais ampla acerca das demandas por orientação no tempo presente, implícitas na tarefa da elaboração crítica do passado. Nesta perspectiva, formulava-se a questão acerca das relações entre a escrita da história como parte do ofício específico do historiador e essa escrita como parte do processo de formação pedagógica (GUIMARÃES 2009, p. 36).

A estratégia de abordagem escolhida partia da interrogação acerca do que poderia estar implícito na ideia de ensino de história, para pensá-lo "como parte de um uso que se procura dar, entre tantos outros possíveis e historicamente articulados, à tarefa de escrever a história" (GUIMARÃES 2009, p. 37). Portanto, a discussão acerca do seu ensino, advertia Manoel Salgado, não podia ser desvinculada de "uma reflexão mais geral acerca dos problemas de uma escrita da história, portanto, de uma reflexão em torno da historiografia e teoria da história" (GUIMARÃES 2009, p. 38, grifos do autor).

Como argumento desenvolvido neste sentido, menos do que enfatizar as diferenças, os distanciamentos ou uma hierarquia segundo critérios de maior ou menor importância entre ambos, tornava-se imprescindível compreender ensino e escrita como instâncias articuladas em um mesmo processo de produção do conhecimento histórico. Pois, continuar a pensá-los como campos autonomizados, argumentava Manoel Salgado, implicaria enormes prejuízos para a história como campo disciplinar, cujos impasses se manifestariam, sobretudo por "uma percepção da falência do ensino de história, do desprestígio do papel 
do professor, mesmo nos espaços sagrados da academia..." (GUIMARÃES 2009, p. 38). Mas, como integrar a discussão acerca do ensino da história ao horizonte de preocupações do exercício do nosso ofício?

Através de uma primeira chave de leitura, era possível situar o ensino da história entre os usos sociais do passado, considerando também a dimensão política sobjacente a esses usos, bem como as suas vinculações ao trabalho da memória coletiva e aos mecanismos da sua reprodução. Deste modo, a reflexão em torno do ensino compartilharia dos mesmos pressupostos e procedimentos da investigação acerca da historiografia, no sentido de privilegiar a interrogação sobre a historicidade e os fundamentos das suas práticas. Contudo, a questão a ser enfrentada era precisamente acerca do papel do ensino de história em meio a uma cultura da memória, entendida como sintoma do que François Hartog chamou de um "regime presentista de historicidade".

É perceptível, na conferência de 2008, a retomada de uma abordagem reflexiva acerca das relações entre historiografia, memória e usos do passado, já sistematicamente desenvolvida por Manoel Salgado, mas, por outro lado, também se torna evidente que o tema do ensino o leva a mobilizar um conjunto de argumentos que não se explicitavam de modo tão claro em textos anteriores, entre os quais é possível identificar a apropriação de elementos da teoria da didática da história de Jörn Rüsen. ${ }^{13}$

A história, desse ponto de vista, não deve e não pode confundir-se com o simples aprendizado de conteúdos, mas deve perseguir a possibilidade de adquirir competências específicas capazes de fundamentar uma reelaboração incessante da experiência temporal com relação às experiências passadas. Mais do que transmitir conteúdos através de uma boa didática, esta teria que dar condições de criar as bases para o estabelecimento de relações com o passado que são necessariamente distintas segundo os presentes vividos (GUIMARÃES 2009, p. 49).

Ainda nas páginas finais do capítulo, a evocação do polissêmico conceito alemão de Bildung serviria para reintroduzir a ideia de formação, como paideia humanista moderna, permitindo pensar o ensino e a aprendizagem da história em uma dimensão mais abrangente, isto é, como processos inscritos entre os fenômenos da cultura. ${ }^{14}$ Para além de sua forte conotação pedagógica, - o termo, em seu sentido de "dar forma e expressividade", também poderia sugerir uma particularidade no modo se conceber a própria história e a sua escrita, fazendo-nos recuperar, quem sabe, a ambiguidade de seu estatuto, já percebida por Leopold von Ranke, quando assinalou que o traço distintivo da história estava em ser, simultaneamente, ciência e arte (GUIMARÃES 2009, p. 44).

Quinze anos passados após as primeiras formulações de Manoel Salgado para uma abordagem renovada dos estudos historiográficos, a posterior profusão de pesquisas no campo da história da historiografia e da teoria da história no

\footnotetext{
${ }^{13}$ A esse respeito, ver RÜSEN 2007, p. 85-94. Sobre a recepção da teoria da educação histórica do historiador alemão no Brasil, ver SCHMIDT; BARCA; MARTINS 2010, p. 11-21.

${ }^{14}$ Para uma discussão da noção de Bildung como conceito aglutinador das ciências do espírito no século XIX, ver GADAMER 2004, p. 44-55.
} 
ambiente acadêmico brasileiro talvez já possa deixar de ser compreendida como mero sintoma circunstancial da entrada da história em uma era epistemológica. No entanto, caberia ainda indagar, teria essa consciência historiográfica dissolvido as fronteiras tão fortemente sacralizadas, através do trabalho contumaz de certa memória disciplinar, entre um historiador que se reivindica artesão e, em nome do ofício, evita sempre ceder às tentações da epistemologia e um historiador que faz da reflexão teórica o fundamento de sua práxis, não se limitando a lançar mão da postura reflexiva apenas em tempos de incerteza?

$\mathrm{Na}$ leitura dos escritos de Manoel Salgado, é possível perceber que, no fechamento de seus textos, não despontam respostas definitivas ou conclusões prescritivas, mas, muitas vezes, emergem indagações que funcionam como o motor para um sistemático e laborioso exercício de reflexão que se vislumbra ao longo de sua produção bibliográfica. E, por isso, não seria despropositado lembrar que, no desempenho do ofício de historiador, entre o artesão e o epistemólogo, um dos traços mais evidentes e memoráveis em sua trajetória talvez tenha sido a atuação como professor de história.

\section{Referências bibliográficas}

ARAUJO, Valdei Lopes de. O século XIX no contexto da redemocratização brasileira: a escrita da história oitocentista, balanço e desafios. In: OLIVEIRA, Maria da Gloria de; ARAUJO, Valdei L. de (org.). Disputas pelo passado: história e historiadores no Império do Brasil. Ouro Preto/ MG: Edufop/PPGHIS, 2012. (Edição Kindle)

DELACROIX, Christian; DOSSE, François; GARCIA, Patrick. Correntes históricas na França: séculos XIX e XX. Rio de Janeiro: Editora FGV, 2012.

FREUD, Sigmund. Totem e tabu. Rio de Janeiro: Imago, 2006 [1913].

FUETER, E. Histoire de I'historiographie moderne. Traduit de l'allemand par Emile Jeanmaire. Paris: Librairie Félix Algan, 1914.

GADAMER, Hans-Georg. Verdade e método I. 6a ed. Petrópolis; Bragança Paulista: Vozes; Editora Universitária S. Francisco, 1997.

GUIMARÃES, Manoel Luiz Salgado. Repensando os domínios de Clio: as angústias e ansiedades de uma disciplina. Revista Catarinense de História, n. 5, p. 5-20, 1998.

. Usos da história: refletindo sobre identidade e sentido. História em

Revista. Pelotas/RS, v. 6, p. 21-36, 2000a.

. Reinventado a tradição: sobre antiquariato e escrita da história. Revista Humanas/IFCH-UFRGS, Porto Alegre, v. 23, n. 1/2, p. 111-143, 2000b.

. História e natureza em von Martius: esquadrinhando o Brasil para construir a nação. História, Ciências, Saúde, vol. 7, n.2, jul-out 2000c, p. 391-413.

A cultura histórica oitocentista: a constituição de uma memória disciplinar. In: PESAVENTO, Sandra J. (org.). História cultural: 
experiências de pesquisa. Porto Alegre: Editora da Universidade/UFRGS, p. 9-24, 2003.

. Historiografia e cultura histórica. Ágora, v. 11, p. 31-47, 2005.

. O presente do passado: as artes de Clio em tempos de memória. In: ABREU, Martha; SOIHET, Rachel; GONTIJO, Rebeca (orgs.). Cultura política e leituras do passado: historiografia e ensino de história. Rio de Janeiro: Civilização Brasileira, p. 25-41, 2007.

. Escrita da história e ensino da história: tensões e paradoxos. In: ROCHA, Helenice; MAGALHÃES, Marcelo; GONTIJO, Rebeca (orgs.). A escrita da história escolar: memória e historiografia. Rio de Janeiro: FGV Editora, p. 35-50, 2009.

. Livro de fontes de historiografia brasileira. Rio de Janeiro: EdUERJ, 2010.

. Historiografia e nação no Brasil (1838-1857). Tradução de Paulo Knauss e Ina de Mendonça. Rio de Janeiro: EdUERJ, 2011.

HARTOG, François. Evidência da história: o que os historiadores veem. Belo Horizonte: Autêntica, 2011.

PALTI, Elias José. Giro linguístico e historia intelectual. Bernal: Universidad Nacional de Quilmes, 2012.

RIEDEL, Dirce Cortes. Narrativa, ficção e história. Rio de Janeiro: Imago, 1988. ROCHA, Helenice; MAGALHÃES, Marcelo; GONTIJO, Rebeca (orgs.). A escrita da história escolar: memória e historiografia. Rio de Janeiro: FGV Editora, 2009.

RÜSEN, Jörn. História viva. Teoria da História III: formas e funções do conhecimento histórico. Brasília: Editora UnB, 2007.

SANTOS, Afonso Carlos Marques dos. A invenção do Brasil: ensaios de história e cultura. Rio de Janeiro: Editora UFRJ, 2007.

SARLO, Beatriz. Tiempo pasado: cultura de la memoria y giro subjetivo. Uma discusión. $1^{\text {a }}$ ed. Buenos Aires: Siglo XXI, 2005.

SCHMIDT, Maria Auxiliadora; BARCA, Isabel; MARTINS, Estevão de Rezende (orgs. ). Jörn Rüsen e o ensino de história. Curitiba: Editora UFPR, 2010. 